\title{
The Economic Environment of Quanzhou and the Financing Research of Small and Medium Enterprises in Quanzhou
}

\author{
Dongdong Weng \\ Quanzhou Normal University \\ Fujian, China
}

\author{
Manping Weng* \\ College of International Trade \\ Liming Vocational University \\ Fujian, China \\ weng28911985@163.com
}

\author{
Xiaofang Wang \\ Liming Vocational University archives \\ Fujian, China
}

\begin{abstract}
Quanzhou is the front position of the reform and opening up,so it one of the most active areas of the private economy,among them,the occupation of small and median enterprises is more than $90 \%$, which us the main force of Quanzhou 's gross production, tax and employment creation.But because of the market competition and the increasing demand for funds, financing is the most important factor that restricts its development.This article first analyzes the middle and small Quanzhou's present situation of the development of the enterprise and then analyze the contribution of small and mediasized enterprises to the Quanzhou economy, and finally analyze financing channels of small and medium enterprises in Quanzhou, in order to explore the reasons for the financing difficulties or small and medium enterprises caused by different financing channels.
\end{abstract}

Keywords_Financing; Financing channels; Enterprises

\section{INTRODUCTION}

Since the 1990s, as a frontier for reform, Quanzhou has emerged from the actual situation and continuously explored and innovated. It has followed a market-oriented, serviceoriented, export-oriented economy, joint-stock reform, and a variety of economies. The economic development model of "coexistence of components" has been built into a road of economic development with the characteristics of a typical hometown of overseas Chinese. The SMEs have achieved unprecedented development. The proportion of small and medium-sized enterprises in Quanzhou has reached more than $90 \%$. Gross production value, taxation, and job creation are all the main forces in Quanzhou. However, due to market competition, the greater the demand for funds by enterprises, the difficulty in financing becomes a constraint to its development. The primary factor.[1]

Foundation Project:

1.2018 Fujian Province Young and Middle-aged Teacher Education Research Project "I Offer Good Strategies for Building New Fujian" (United Front Work Project) (Key Funding Project) (JZ180019).

2.Fujian Provincial Education Science "Thirteenth Five-Year Plan" 2017 Cross-Strait Vocational Education Special Research Project(FJJKHX17-077).

3.Quanzhou Normal University Student Innovation and Entrepreneurship Training Program Project Funding (Project No.: 201810399120).

\section{Development Status of Small And Medium-Sized ENTERPRISES IN QUANZHOU}

With the development of reform and opening up, the people of Quanzhou hold high the great banner of Deng Xiaoping Theory, guided by the important thinking of the "Three Represents" and the scientific development concept, constantly forging ahead, carrying forward the spirit of love and hard work, and seize the opportunity. Bold practice, starting from the experience of "one supplement", township enterprises paving the way, the great development of foreigninvested enterprises, striding into the economic development road and the economic development stage of the regional economic exhibition, and embarking on a "market regulationoriented, outward-oriented On the basis of a type of economy and joint-stock cooperative system, and a variety of ownership systems to develop together. "The path of economic development with Chinese characteristics, the economic strength has reached a new level every few years, creating a "Jinjiang model" and "Quanzhou phenomenon" in Fujian Province. Even the whole country has become the fastest growing economic region and the most active one, creating a new and glorious history of development in Quanzhou.

Most of the "three-capital" enterprises in Quanzhou are engaged in foreign investment by small and medium-sized enterprises, and there are very few enterprises that are actually funded by foreign investors. Counties (districts, cities) in Quanzhou also include grafted "three-funded" enterprises in SMEs. At present, there are only 985 state-owned enterprises in Quanzhou, about $6 \%$ of the total number of enterprises in the city.[2]

At present, Quanzhou SMEs are involved in various industries. Among them, the proportion of SMEs in the primary industry is about $3 \%$, mainly in the fields of agricultural comprehensive development, aquaculture, livestock breeding, and flower cultivation; most of them are 
concentrated in the secondary industry and also account for $85 \%$ of the total number of companies. Including all industries in the manufacturing industry, such as mining, food, paper and building materials, clothing, packaging, toys, etc.; enterprises in the tertiary industry accounted for about $12 \%$, mainly catering and entertainment, wholesale and retail industries.

\section{QUANZHOU SME FINANCING STATUS}

Affected by the international financial crisis and the further advancement of economic globalization, the competition among global enterprises in the post-crisis era will be even more severe. At the same time, coupled with a serious shortage of domestic consumer demand, Quanzhou enterprises must not only compete with their domestic counterparts for the domestic market, but also at the same time. It also faces trade protectionism from governments in Europe and the United States, such as increased regulatory tariffs, which have greatly impacted the survival and development of Quanzhou enterprises.The main factors affecting the financing of SMEs in Quanzhou include the following[3].

\section{A. Banking and Non-banking Financial Structure Factors}

We have concluded from the analysis of the loan analysis of the four state-owned banks in Quanzhou by the Quanzhou Branch of the People's Bank of China that the four stateowned banks in Quanzhou monopolize $70 \%$ of the deposit, while small and medium-sized financial institutions only account for $30 \%$. Small and medium-sized financial institutions spend a lot of money on government bonds, resulting in insufficient supply of funds for SMEs. Therefore, the financing of SMEs in Quanzhou is at a disadvantage.

\section{B. Social Culture and Financial Policy Factors}

The management of small and medium-sized enterprises in Quanzhou has a strong family characteristics. In some important jobs, it is basically the relatives of the enterprises that control the people, thus making management difficult to be transparent. Since many SMEs default on bank loans and interest, the information between banks and SMEs is asymmetrical. Therefore, many SMEs can hardly obtain loans from banks. Therefore, in order to ensure normal production, they are forced to turn to private lending.[4]

The shortcomings of financial policy are mainly reflected in the following two aspects: First, the innovation of financial products and services and financial reforms are not guaranteed by relatively complete financial laws and regulations; second, there are contradictions and contradictions in the legal norms themselves; Imperfections in content regulations are difficult to operate in practice. These also greatly hindered the financing of Quanzhou SMEs. Quanzhou is currently a national financial reform pilot zone. The following measures should be improved: improve the legal system for financial institutions to exit the market; and improve the risk prevention mechanism of financial institutions.

\section{Guarantee Institutions}

At present, the scale of Quanzhou guarantee institutions is relatively small compared to the development of small and medium-sized enterprises, which is difficult to meet the financing needs of small and medium-sized enterprises in Quanzhou. The main business of many guarantee institutions in Quanzhou is not the guarantee business, but the "hanging sheep head selling dog meat". The main business is to help corporate loans "cross the bridge" and participate in private lending activities, that is, loan sharking. In addition, the guarantee agencies themselves have internal management deficiencies, lack of effective risk management mechanisms and other defects. At present, Quanzhou SME guarantee institutions mainly rely on the experience of business personnel for many years in the identification of guarantee risks. There is no scientific risk identification and evaluation system, so it is easy to cause decision-making mistakes. The guarantee agencies and the banks are independent of each other and have not played a mutually beneficial role. The guarantees that companies originally joined in guarantee agencies have greatly reduced the credit risk of banks.[5]

\section{CONTRIBUTION OF QUANZHOU SMES TO QUANZHOU ECONOMY}

\section{A. The Contribution of SMEs to Quanzhou Economy}

The contribution of SMEs to Quanzhou's economy is mainly reflected in the following aspects:

1) The development of SMEs has become the core strength of Quanzhou's national economy: The number of SMEs with a certain scale in Quanzhou reached 142,685, and the total value created by SMEs accounted for $47.3 \%$ of Quanzhou's gross domestic product (GDP), and the total tax paid by Quanzhou accounted for 58.3\% of Quanzhou's total tax. It is the main source of finance for counties, townships, and towns in Quanzhou. It is a key factor for Quanzhou to develop the economy of the Hercynian Sea and plays a key role in promoting Quanzhou's economic development.

2) The development of small and medium-sized enterprises is conducive to the industrialization reform of Quanzhou and promotes the urbanization of rural areas: The coastal areas have changed from agricultural economy to industrial economy in the 1990s, and economic industrialization has promoted the urbanization process in rural areas.

3) SMEs have created a large number of employment opportunities: Small and medium-sized enterprises have created a large number of employment opportunities. There are many small and medium-sized enterprises in Quanzhou, which have solved the problem of rural surplus labor employment and provided a large number of employment opportunities for the neighboring provinces of Jiangxi and Anhui.

4) The development of SMEs has improved the export of foreign trade: Quanzhou is a famous hometown of overseas Chinese. After the reform and opening up, many overseas Chinese returned to their hometowns to establish small and medium-sized "three-funded" enterprises, resulting in the vast majority of products produced by enterprises being sold 
abroad; at the same time, these "three-funded" enterprises also expanded a large number of export-oriented township enterprises. Private company.

\section{B. Problems in the Development of SMEs in Quanzhou}

SMEs are the main force of industrial development in Quanzhou. Under the pressure of the external environment, such as the appreciation of the renminbi, lack of internal consumption, economic depression, rising raw materials, and financing difficulties, Quanzhou's SMEs will carry forward the spirit of "sincerity and hard work" and will continue to improve in the midst of change. Resist anti-risk capabilities and strive to create new growth points. However, there are still the following problems in the development of Quanzhou SMEs:

1) The imbalance of regional economic development is the "trauma" that restricts the development of small and mediumsized enterprises in Quanzhou: The development of SMEs in different regions is uneven, for many reasons. First, the development of SMEs is related to geographical location, local government support and economic environment. Second, the development of SMEs is related to whether the region has a relatively complete industrial chain. Third, the development of SMEs is related to industrial advantages and technological content.

2) The lack of talent and the lack of innovation by enterprises are the "internal injuries" that restrict their development: The relevant departments once conducted surveys on 28 innovative SMEs in the Jinjiang Industrial Zone and other industrial zones. About $29 \%$ of companies believe that the talent problem is serious, especially the lack of excellent management personnel. Most of the employees of the company are ordinary employees with low education level. There are less than 3 employees who have scientific research capacity per 10,000 employees. The quality structure of talents is irrational. Persons with high-quality, intermediate-level or higher professional titles are generally older and account for more. The proportion of employees is relatively low, accounting for only $5.7 \%$ of the total. The shortage of innovative, compound and export-oriented talents is particularly prominent.

3) The shortage of funds and financing difficulties are the "hard injuries" that restrict the development of SMEs. In the past few years, the rapid development of small and mediumsized enterprises in Quanzhou has two reasons: First, banks do not require high loan conditions, and second, private finance is more active. State-owned banks have strengthened the control of credit risk, and small and medium-sized enterprises in Quanzhou are facing difficulties in financing; private lending has shrunk due to their own poor reliability and the country's reorganization of financial order.

\section{QUANZHOU SMEs FINANCING CHANNEL ANALYSIS}

Quanzhou SME financing includes the following types:

\section{A. Bank Loans}

Bank loans are the most direct way for SMEs to obtain funding. Like other places, Quanzhou Commercial Bank Credit is mainly used for large enterprises and state-owned enterprises. It is basically very difficult for private SMEs to finance through their own credit. The main reason is that in recent years, commercial banks have prevented financial risks, strengthened internal control, and reduced a series of credit loans. They have strict requirements on loans, mainly requiring mortgages or guarantees, while the collaterals of small and medium-sized enterprises in Quanzhou are lacking. The amount of funds required by small and medium enterprises in Quanzhou.

\section{B. Bond Financing}

Quanzhou's small and medium-sized enterprises are generally small in size, with insufficient funds and credibility, and there are legal restrictions. Only a small number of small and medium-sized enterprises can meet the issuance of bonds. According to financial knowledge, we know that any financial innovation product has its defects, the same is true for collective debts, with high financing costs and uncertainty of time, and poor compatibility. For example, a company is pledged to Deutsche Bank through a bond of Hua Xia Bank, and a loan of 100 million US dollars is placed at Deutsche Bank. The company deposits an equal amount of RMB into Hua Xia Bank, which is a low-risk business for Hua Xia Bank, which can reduce exchange rate volatility for enterprises. risk. Therefore, both banks and businesses are win-win businesses.

\section{Equity Financing}

Equity financing mainly refers to the liquidity needed by enterprises to raise capital through equity transfer, stock addition, and stock expansion. Equity financing compared to other financing methods, because of the smaller business constraints brought about by the financing, the company's increase in net assets in the previous period can further help companies obtain funding needs. For small and medium-sized enterprises, financing from other companies through direct investment such as mergers, acquisitions, joint management, and strategic alliances can achieve the purpose of corporate financing. However, since most small and medium-sized enterprises in Quanzhou belong to the family business, they are concerned about the control dilution, therefore, Some SMEs exclude external equity financing. For enterprises, equity financing increases the company's financing channels and reduces the company's financing costs.[6]

\section{Pawn Financing}

Pawn loans mainly provide the pawn company with financing for the pawn company's valuable things. It is characterized by quicker turnover and no need for any other guarantees. As long as the objects are valuable to the pawn company, they can be quickly cashed into the pawn company. For all registered enterprises in Quanzhou, SMEs account for $90 \%$, and the funding gap is very large. Therefore, in order to meet the needs of these SMEs, the development of private financing is very important. However, due to the high cost and instability of private financing, some SMEs have to bear the 
heavier financing and financing costs. Private financing costs are higher, and banks have strict control on entry barriers, which in turn has promoted the vigorous development of the pawn industry. Therefore, pawn financing has become one of the financing channels for enterprises.

\section{REFERENCES}

[1] X.H. Chen and J. Liu, "Research on the Evolution of China's SMEs' Financing Structure and Financing Methods," China Soft Science, vol. 12, 2003. pp. $30-33$
[2] X.C. Xu, "Reflections on Several Issues of SME Financing," Journal of Nanjing University of Finance and Economics, vol. 01, 2011. pp. 61-64

[3] Y.C. Hu, "Investigation and Thinking of SME Financing," Management World, vol. 04, 2004. pp.131-134

[4] W.S. Liu, "Analysis of financing difficulties for SMEs," Science and Technology Information, vol. 32, 2006. pp. 70-74

[5] X.M. Liu and X.H. Lin, "Discussion on U.S. SMEs' Financing Channels - Concurrently Discussing the Enlightenment of Improving China's SME Financing System," Journal of Fujian Institute of Socialism, vol. 02, 2003. pp. 91-94

[6] J.Q. Lu, Study on the efficiency and supervision of China's small and medium-sized commercial banks, Jilin University, 2010 pp. 35-3. 